\title{
THE APPLICATION OF EMG TO THE STUDIES OH PHYSICAL EXERCISES
}

\author{
Hideji MATSUI and Mitsumasa MIYASHITA \\ Department of Physical Education \\ General Education School of \\ University of Nagoya
}

As Kato (1962)4) alseady repprted, the studies in kinesiology were started after World War II in Japan. As is often the cases with the beginning of a new study, the first decade from 1950 to 1959 was mostly devoted to the accumulation of research results in other countries. Since 1960, however, original studies in kinesiology have been undertaken by many researchers in Japan.

EMG is unique in revealing what a muscle actually does at any moment during various movements and postures (Basmajian, 1967). It can be, therefore, said that EMG study is indispensable for kinesiology. In the present paper, the authers intended to introduce the development of electromyographic studies in the field of physical education in Japan.

\section{Improvement of apparatus}

Electrodes: There are two types of electrodes (surface and inserted) which are used for the study of muscular activitice, and each has its advantages and limitations. The surface electrodes is widely used for the study of human movements. The silver cups (5mm in diameter) for EEG were generally used for EMG. But recently those silver cups were rubbed in. The rubber silver cup electrodes are better for recording EMG of vigorous exercises (Fig. 1).

Integrators: EMG recorded by surface electrodes can deal only with the qualitative analysis of muscle activities. Therefore several investigators have tried to record the electrical activity of muscle quantitatively. Ikai (1963) ${ }^{3)}$ performed the integration with a modified Miller's circuit in order to observe muscular endurance in the elbow flexor (Fig. 2). EMG recorded in posttraining period showed less voltages compared with that in pre-training at the same number of contractions, and they increased to the same maximum level at the moment of exhaustion. Miyashita (1969) ${ }^{8}$ ), using a Miller's circuit, studied the relation between muscular tension and integrated EMG under isotonic contraction of elbow flexors (Fig. 3). Fig. 4 shows that the electrical activities dur-

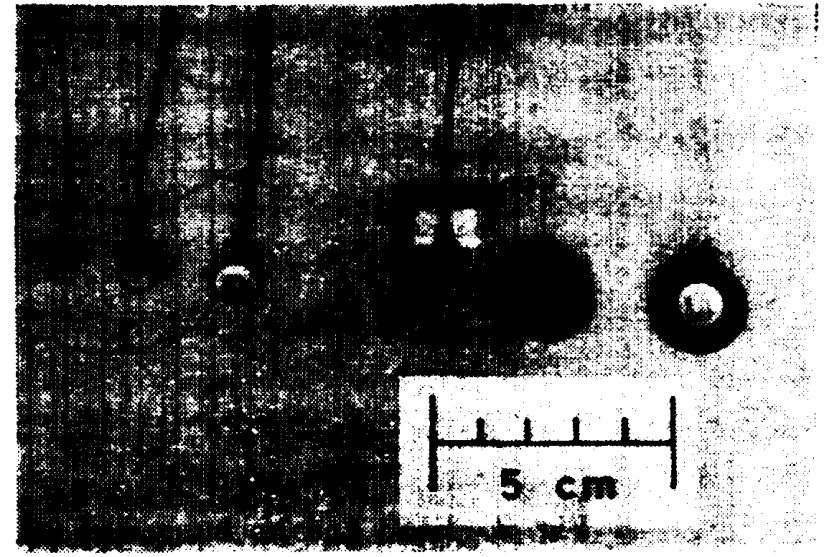

Fig. 1. EEG electrodes and rubbered electrodes for EMG 
Before training $(6 / 5)$

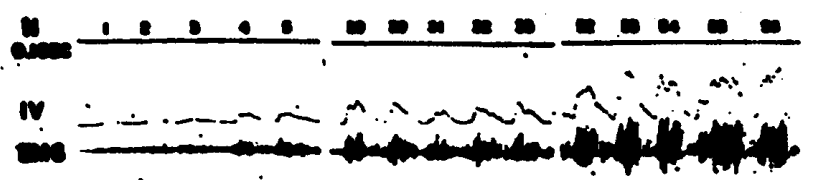

$\mathbf{N}=$ Number of contraction

IV = Integrated EMG

EMG $=$ EMG of M. Biceps brachii

After 2 weeks of training $(6 / 21)$

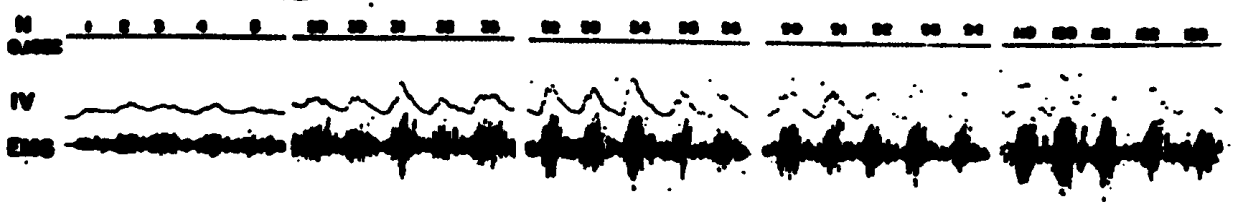

After 6 weeks of training (7/19)

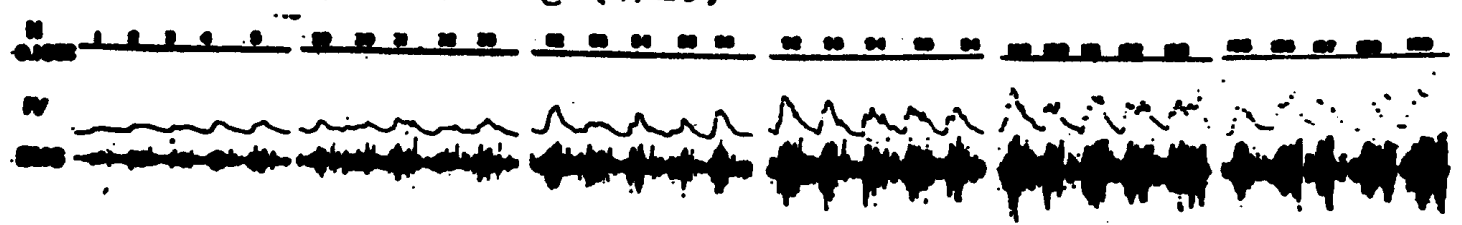

Fig. 2. Electromyogram of the elbow flexor during ergometer works against a constant load at different stages of training.

(Ikai \& Ishii 1963)

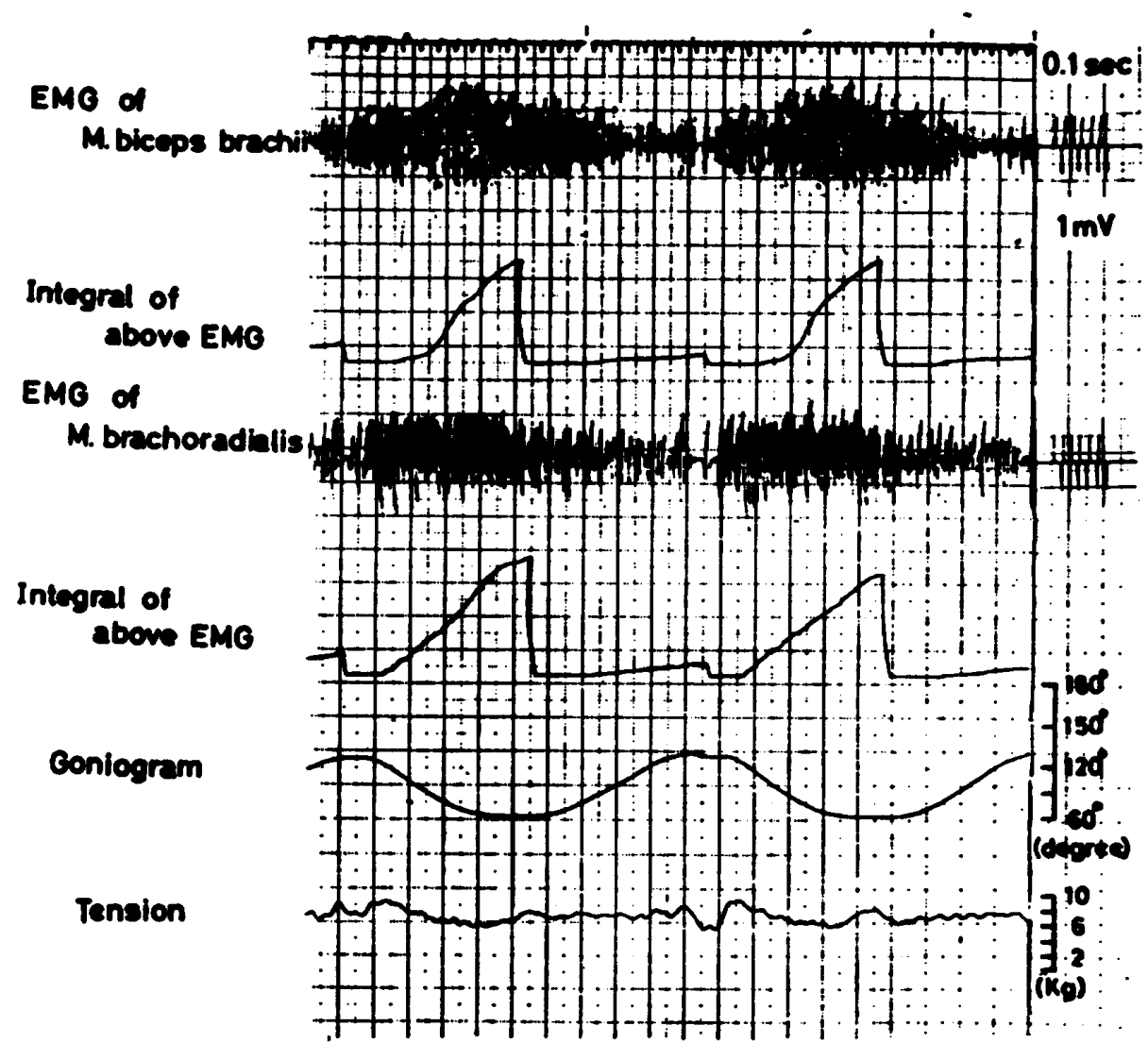

Fle. 3. EMG and its integrated voltage of elbow flexors under isotonic conditions with recordings of electrogoniogram and of tension. Subject: male subject aged 35 . (Miyashita, et al. 1970) 
ing shortening increased with tension and the rate of increment of electrical activities increased with velocity of shortening.

Recorders: EEG recorder with tweleve channels had been widely used for EMG recordings. Thereafter the multipurpose polygraph has been developed. The recent polygraph is capable of recording EMG together with the other phenomena such as the movement of joint, and the force developed by foot. The electromyographic tracings can reveal the activities of muscles more precisely and clearly together with the other mechanical recordings of leg or foot.

Matsui (1970)7) tried to record EMG of leg muscles together with foot pressure and electrogoniogram of knee ioint. The record of Fig. 5 shows the physiological function related to mechanical ones such as ground reaction and motion of knee joint.

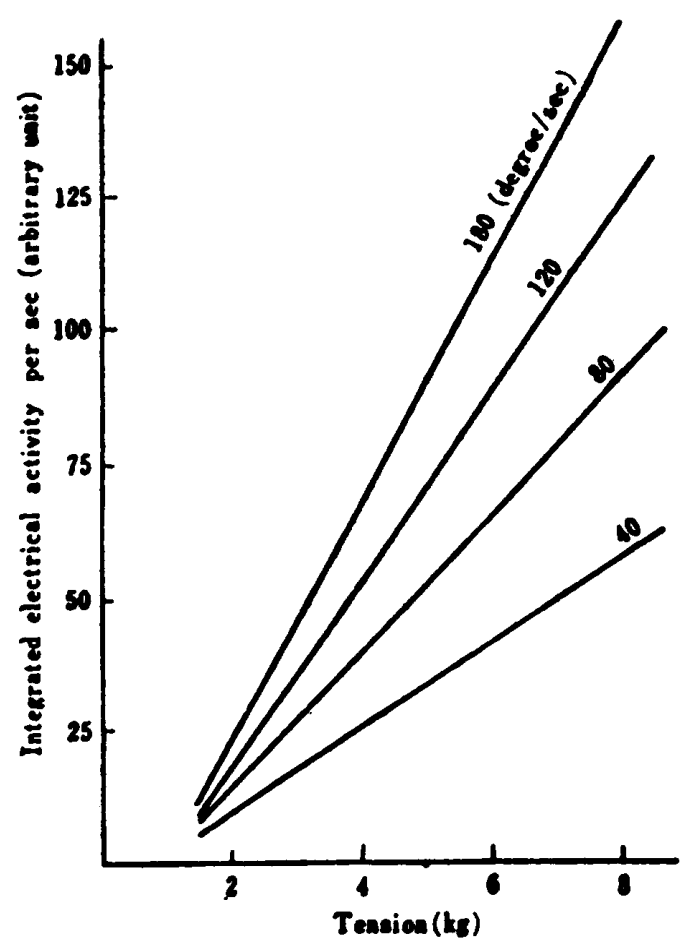

Fig. 4. The relation between electrical activity and tension at the different rates of angular velocity. (Miyashita, et al. 1970)

Ruaning

Time in 0.1 see.

Pressure curve of toe
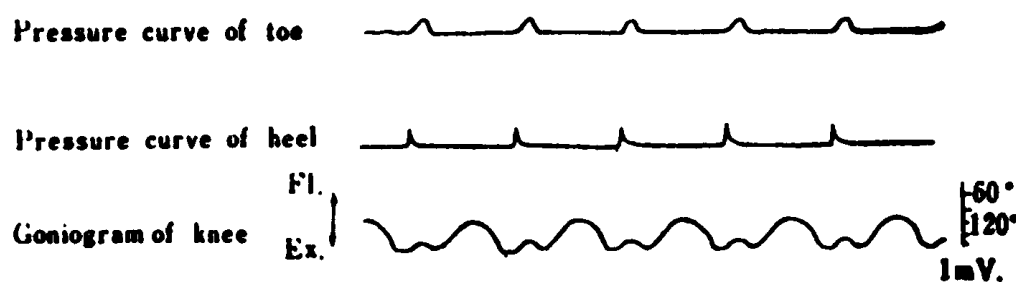

M. slut eus maximus

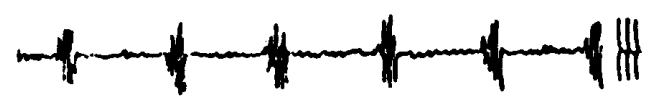

M. biceps femoris

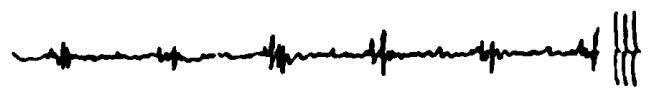

M. rectus femoris

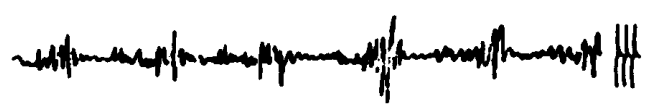

M. tibialis anterior

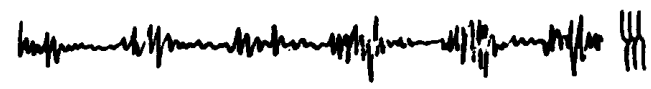

M. esstrocnemius

Treadmill speed

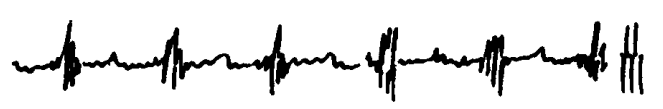

$300 \mathrm{~m} / \mathrm{min}$.

Fig. 5. EMG of leg muscles with the recordings of pressure curves and the electrogoniogram of knee joint.

(Matsui, et al. 1970) 


\section{Studies on physical exercises}

The studies on physical exercises can be generally divided into two groups. The first group is for the local exercises and the other is for the whole body exercises. As for the former, there were several studies on shoulder, elbow, hip and knee joints.

Okamoto (1967) 13) worked on the EMG of shoulder muscles during elevation of the upper arm in various vertical planes and showed the discharge patterns in EMG in relation to each direction of elevation. The same author (1968)14) studied on the action of two joints muscles. That is, EMG of rectus femoris was recorded during knee extension at various postures from sitting to lying. Niwa (1970) ${ }^{12}$ ) recorded EMG of elbow muscles and hip muscles under the maximum isometric contractions at respective angles of each joint. Matsui6) and Miyashita (1970) ${ }^{7)}$ performed the experiments to reveal the relation between muscular tension and integrated EMG of elbow muscles under both isometric and isotonic conditions (Fig. 4).

As for the whole body exercises, there were a number of studies. In order to find the common patterns of muscular activities, EMG of rest standing in man was recorded by Masaki (1961) 5). Takagi et al. (1961) ${ }^{15}$ ) recorded EMG of leg muscles to study the instep kick action of a soccer ball. The recordings indicated that the main muscles used in this movement were $M$. quadriceps femoris and the adducent muscles. It was reported by the same authors (1961)16) that M. gluteus maximus and M. gluteus medius were active in extension of hip joint, and M. vastus medialis was active in extension of knee joint during jumping vertically.

The first recordings of EMG of swimming in a pool were recorded by a multiple channel recorder (Ikai et al., 1964)2). To record EMG, the surface electrodes were used, which being attached to the skin with a special device. Namely, Celloidin and Vinyle Chloride together with plaster were used to fix the electrodes on the skin. Also the body of the swimmer and the water in the pool were completely grounded to remove electrical disturbances.

Mizutani et al. (1969)10) compared the negative and the positive works done in the various types of the movements, such as chinning, two hands curl, going up and down stairs, pedalling, squat and jumping from the view point of EMG. Miyashita et al. (1970) ${ }^{9)}$ recorded the EMG of leg muscles during walking and running at various speeds. It was reported that there was a regular relation between integrated electrical activities and walking or running speed (Fig. 6). Toyoshima et al. (1970) ${ }^{17}$ ) worked on the EMG of arm muscles during throwing the various kinds of balls in sizes and weights. The results indicated that there was a clear difference in muscular activities between over or shoulder hand throw and under hand throw, and also there was a great difference between throwing the balls which were small enough to grasp and the balls which were too large to grasp.

Both apparatus and technique in EMG study were so much developed that, in future, EMG will be applied more and more to the studies of physical exercises. One of the problems which should be tackled in kinesiology is the analysis of the various cxercises performed by the most excellent players. In that analysis, EMG will more pricisely reveal how the performer controls his muscles in timing, in grading and in spicing. Then the 


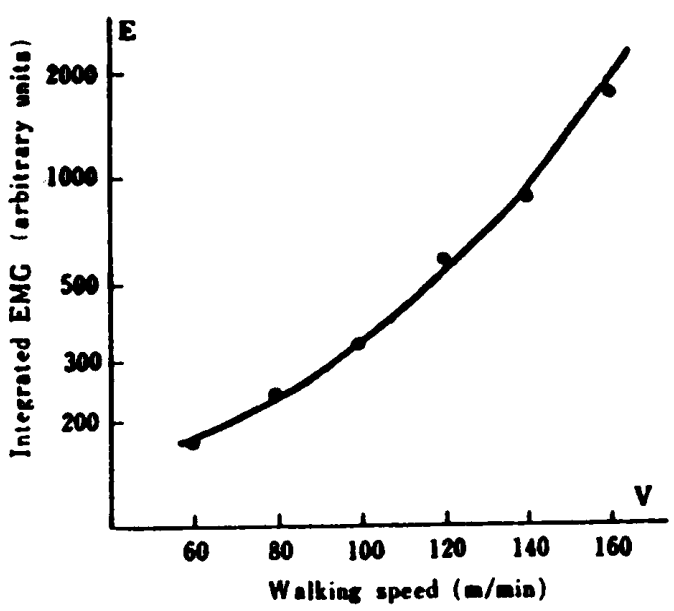

$\log E=0.575 \times 10^{-4} \cdot V^{2}-0.265 \times 10^{-2} \cdot V+2.208$

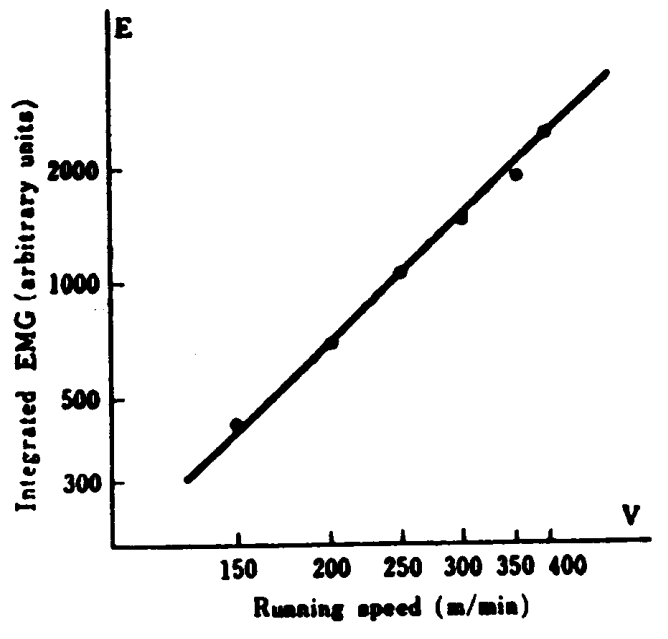

$E=0.044 \times V^{1.11}$

Fig. 5. Left; The relation between integrated electrical activity (logarithm) and walking speed.

Right; The relation between integrated electrical activity and running speed (both in logarithm). (Miyashita, et al. 1970).

question how to teach a physical exercise efficiently will be answered by EMG study in addition to film and mechanical studies.

\section{References}

1) Basmajian, J. V.: Muscle alive. The Williams \& Wilkins Com. 1967.

2) Ikai, M., K. Ishii and M. Miyashita.: An electromyographic study of swimming. Research J. of Physical Education. 7; 4. 47-54. 1964.

3) Iksi. M. and K. Ishii. : An electromyographic study on physiological and psychological limit of human muscle strength. International EMG Meeting, Copenhagen. 1963.

4) Kato, K.: The development of researches in physical education in Japan. Research J. of Physical Education. 6; 3, 4. 54-56. 1962.

5) Masaki, T.: Studies on postures. (II). (in Japanese with English rèsumè). Research J. of Physical Education. 5; 2. 21-27. 1961.

6) Matsui, H., et al.: Electromyographic study on positive and negative works (I). (in Japanese with Englishrèsumè). Research J. of Physical Education. 14; 1. 39-43. 1969.

7) Matsui, H.. et al.: Transducer for measurement of pressure distribution in the foot. Research Bulletin (Dept. of General Education, Nagoya Univ). No. 14. 69-75. 1970.

8) Miyashita, M., et al.: Electramyographic study on positive and negative works (III) (in Japanese with English rèsumè). Research J. of Physical Education. 14; 2. 98-102. 1969.

9) Miyashita, M., et al.: The relation between electrical activity in muscle and speed of walking and running. Research Bulletin (Dept. of General Education, Nagoya Univ.). No. 14. 76-84. 1970.

10) Mizutani, S., et al.: Electromyographic study on positive and negative works (II), (in Japanese with English rèsumè). Research J. of Physical Education. 14; 2. 93-97. 1969.

11) Niwa. N.: Relation between joint angles and muscle strength-in the case of arm strength-(in Japanese with English rèsumè). Research J. of Physical Education. 1E; 1. 48-53. $197 \mathrm{C}$.

13) Okamoto, T. and K. Takagi.: Electromyographic study of elevation of arm. Research J. of 
Physical Education. 11; 3. 127-136. 1967.

14) Okamoto T.: Electromyographic study of the function of M. rectus femoris. Research J. of Physical Education. 12; 3. 175-182. 1968.

15) Takagi, K., et al.: Electromyographical study of the Kick (in Japanese with English rèsumè). Research J. of Physical Education. 5; 3. 79-83. 1961.

16) Takagi, K., et al.: Electromyographical analysis of Sargent Jump (in Japanese with English rèsume). Research J. of Physical Education. 5; 3. 83-88. 1961.

17) Toyoahima, S., et al.: Electromyographic studies on throwing. Research J. of Physical Education. $15 ; 2.1970$. 